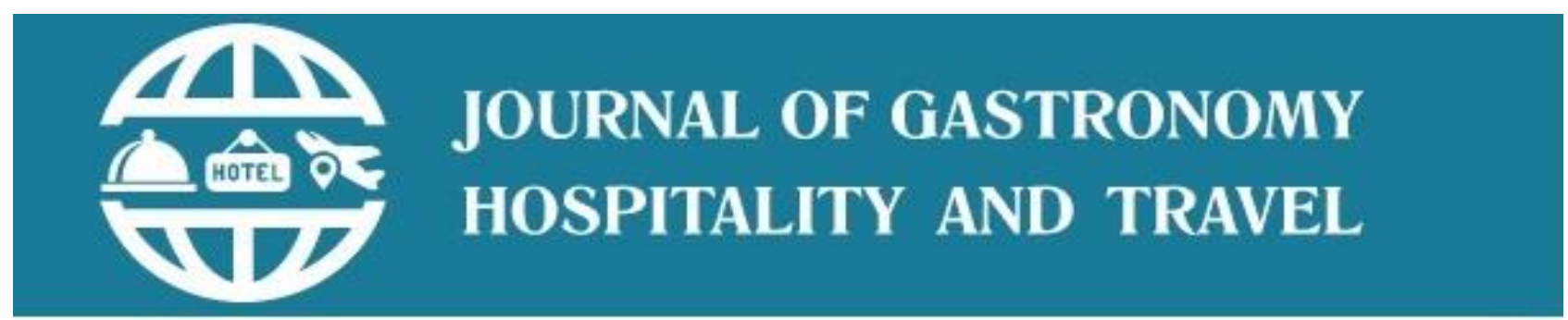

ISSN: 2619-9548

Journal homepage: www.joghat.org, http://dergipark.gov.tr/joghat

Journal of Gastronomy, Hospitality and Travel (JOGHAT)

2020 - Volume: 3 Number: 1

Page : 87-100

Received : 28/04/2020

Revised: 10/06/2020

Accepted : $12 / 06 / 2020$

\title{
Research Article \\ SENSORIAL ACCEPTABILITY OF GLUTEN FREE MALAYSIAN TRADITIONAL KUIH FROM LEFTOVER COCONUT PULP FLOUR
}

\author{
Aziz Caliskan ${ }^{1}$ (https://orcid.org/0000-0002-1881-0680)

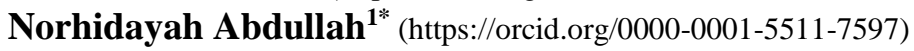 \\ Noriza Ishak ${ }^{2}$ (https://orcid.org/0000-0002-0921-5011)
}

${ }^{1}$ Foodservice Management, Faculty of Hotel and Tourism Management, University Technology Mara, Puncak Alam, Malaysia.

${ }^{2}$ Gastronomy, Faculty of Hotel and Tourism Management, University Technology Mara, Puncak Alam, Malaysia.

\begin{abstract}
Gluten is a protein found in cereals, giving foods a pleasant elasticity and body structure. Cereal products, containing gluten are rich in dietary fibre. Although gluten plays a vital role in food production, it is harmful to gluten intolerant people (GIP). Hence, GIP is forced to follow a lifelong gluten-free diet, affecting their dietary fibre intake, essential against diarrhoea, constipation and colon cancer. Coconut (Cocos Nucifera) is the largest local commodity after rice in Malaysia. Coconut meat is usually processed for coconut water, coconut milk and coconut oil, while the leftover coconut pulp (LOCP) is disposed or used for livestock feeding. However, this LOCP is rich in dietary fibre and gluten-free, making it the best alternative for making gluten-free Malaysian Traditional Kuih (MTK), suitable for GIP. Apam Balik Kuih (ABK) is a highly popular MTK. Therefore, this study focused on providing gluten-free MTK from leftover coconut pulp flour (LOCPF), high in dietary fibre and consisting of three formulations; 60\% LOCPF and $40 \%$ rice flour (F2), $100 \%$ LOCPF (F3) and a control sample from 100\% wheat flour (F1). Two sensorial evaluations were conducted (semi-trained panel and consumer acceptability). The semi-trained panel showed similar results for appearance, texture, and mouthfeel for all variants of all, F3 was rated as unpleasant tasting. F1 was graded medium brown, while F2 and F3 were graded brown in colour. F2 was rated as the best for overall acceptability. For consumer acceptability, F1 rated "slightly like" in all criteria. F2 rated "neutral" for colour, texture, mouthfeel and "slightly like" for appearance, taste and overall acceptability. F3 rated "neutral" in all criteria. Among all, F2 showcased the best formulation as depicted by higher mean score rated. Based on these results, LOCPF proved a good gluten-free alternative flour with high fibre content, beneficial for pharmaceutical and food industry application.
\end{abstract}

Keywords: Gluten-Free, Semi-Trained Panel, Consumer Acceptability, Leftover Coconut Pulp Flour, Malaysian Traditional Kuih

\section{INTRODUCTION}

Malaysia is a peninsula country in the southeastern part of Asia. The country has three ethnic groups, which are typical or indigenous Malays, Chinese Malays, and Indian Malays (Nazri, Raji, Ab, Adibah, \& Ishak, 2017). There are varieties of baked products made out of the ordinary home-based ingredient in Malaysia, such as wheat flour, rice flour, coconut milk, gula Malaka, etc. (Opalyn Mok, 2016). One of the leading causes of this is that the cuisine of the country is influenced by ethnic groups. This naturally has a

"To cite this document: Caliskan, A., Abdullah, N. and Ishak, N. (2020). Sensorial Acceptability of Gluten Free Malaysian Traditional Kuih from Leftover Coconut Pulp Flour, 3(1), 87-100. DOI: 10.33083/joghat.2020.33

Corresponding Author: azizcaliskan96@gmail.com 
major impact on baked products (kuih). Kuih is a generic name for baked kuih in Malaysia. It can be divided into two general categories: Sweet and savoury (Nazri et al., 2017). In ancient times, kuih used to be popular food for religious holidays and celebrations. However, today, they have transited from being an occasionluxury to a regular nosh and can be found easily in lots of restaurants and local markets (Hamzah, Karim, Othman, Hamzah, \& Muhammad, 2014; Opalyn Mok, 2016). One of the most famous Malay street food is Malay Apam Balik Kuih (ABK) 'turnover peanut pancake'; 'Chin Loong Pau' in Chinese), a famous snack food in Malaysia. In China, it is a popular in Fujian, known as Min-Jian-Kue and it was later adopted by Hokkien as Ban-Jian-Kue. Malay ABK is a popular snack product, which either a thin crust or thick and fluffy, sweet peanut pancake, consumed at any time of day by the locals. (Timothy G. Roufs \& Kathleen Smyth Roufs, 2014). According to the Malaysian food governing authority Jabata Warisan Negara JWN, (2019), the country has 38 recognized traditional kuih recorded in the traditional foods list. Out of these 38 kuih, 20 have potential gluten content (USDA, 2018).

Gluten is a protein, containing essential components, encompassing gliadins and glutenin, which are highly regarded by dough manufacturers. They help to provide elasticity as well as the physical structure of the dough (Biesiekierski, 2017; Jnawali, Kumar, \& Tanwar, 2016). For these reasons, gluten is essential in food technology. However, there are people with Gluten Related Diseases (GRD), to which the consumption of gluten can be harmful. GRD is associated with autoimmune system disorder, allergy and Non-Gluten Celiac sensitivity. Additionally, most of the food products, that contain gluten are high in dietary fibre, which plays a vital role in enhancing the life and function of the microorganisms of the intestine (Biesiekierski, 2017; Hager, Axel, \& Arendt, 2011). Although dietary fibre is of such importance to humans' intestinal life, research showed that gluten-free diet is scarce in it (Hager et al., 2011; Lee, Ng, Dave, Ciaccio, \& Green, 2009; Öhlund, Olsson, Hernell, \& Öhlund, 2010; Shepherd \& Gibson, 2013). This dietary fibre is vital in preventing conditions, such as diarrhoea and other secondary conditions, like diabetes and colon cancer (Hager et al., 2011). Leftover coconut pulp (LOCP) can be a good source of dietary fibre and a possible replacement for wheat. (Barge \& Divekar, 2018). The coconut (Cocos nucifera) is the second most-produced product in Malaysia and one of the most important economic products in the world. It is used to satisfy various needs such as food, fuel, material for constructions, and clothing (Adkins, Foale, \& Harries, 2010). Today, the main products produced from coconut in factories are coconut water, coconut milk, and oil; However, residues of coconut milk (i.e.) are disposed of as waste or used as livestock feeds (Seow \& Gwee, 1997). Coconut milk residue is a diet rich in fibre and protein content (Barge \& Divekar, 2018). Therefore, a low-cost dietary fibre and protein-rich, gluten-free flour can be obtained from this residue and be used for making gluten-free products.

Sensory quality of food products has been accepted as an important factor since the beginning of the food industrialization process due to its effect on the overall quality of the product. For consumers, eating quality (aroma, taste, flavour, tactile properties and appearance) is a decisive factor in food acceptance. Consequently, quality in this context is (measured by) the preferences of the consumers and the quality level is defined by the abundance of desired properties and absence of unwanted traits. Quality is, therefore, a better understanding of the consumer's favourite and quality grades with the degree of desirable qualities and the absence of undesirable properties. Therefore, flavour and food quality is prioritized in choosing and consuming a food product, while other criteria, such as nutrition and health, are subsidiary. Descriptive sensory analysis techniques are widely used as an indispensable tool for product development. The quality of the performance of the sensory evaluators is the greatest and most important factor for the successful implementation of the methods. Hence, recruitment and screening have essential implications for the effectiveness of the training process and the development of sensory performance (Anupama, Khan, \& Radha, 2018).

\section{METHODOLOGY}

This section shows the materials and the steps used in this study as follows, flour preparation, preparation of apam balik kuih, sensorial evaluations (semi-trained panel, and consumer acceptability), and statistical analysis.

\subsection{Preparation of Leftover Coconut Pulp Flour}


The LOCP was separated into 70 grams and placed in the dehydrator, Excalibur 3926TBX (USA). In the dehydrator trays, the LOCP were evenly distributed at the height of $1 \mathrm{~cm}$. The LOCP was dried at $40{ }^{\circ} \mathrm{C}$ for $3 \mathrm{hrs}$. These are the optimum drying parameters to obtain LOCP flour as obtained by the preliminary studies. The dried LOCP was removed and subjected to the grinding process by using conventional food grinder (PANA-MX-800) for $1 \mathrm{~min}$. Finally, after the grinding process, the dried LOCP was sieved using a conventional sieve with $0.18-0.20 \mathrm{~mm}$ particle size. The obtained LOCP flour was then stored in an airtight container at a temperature of $4{ }^{\circ} \mathrm{C}$ prior to analysis.

\subsection{Preparation of Apam Balik Kuih}

To prepare the original ABK, First, the ingredients were weighed. Then, the dry ingredients were mixed in a mixing bowl. Afterwards, they were placed in a blender and mixed with liquid ingredients (Philips, HR2056/00, Netherlands) for a duration of $60 \mathrm{sec}$. The mixture was placed in an airtight container and allowed to stand at 2 to $4{ }^{\circ} \mathrm{C}$ for 20 minutes. A non-stick pan was heated for cooking, and butter was added to it. After the butter had melted, $125 \mathrm{ml}$ of the mixture was poured onto the pan and left to cook for 8 minutes and 10 secs on low heat (i.e. $90.55^{\circ} \mathrm{C}$ ). After the $\mathrm{ABK}$ was cooked, $5 \mathrm{~g}$ sugar, $12 \mathrm{~g}$ corn cream, and $5 \mathrm{~g}$ peanuts were mixed and spread on its surface. In the last step, the dessert was folded in half.

To prepare the formulated ABK, a couple of ingredients were introduced, which are LOCPF and xanthan gum. The respective ingredients mentioned in the materials list above were used to prepare both the ABK made from mixture flour (60\% LOCPF and 40\% RF) and ABK made from 100\% LOCPF. The same steps used to prepare the original $\mathrm{ABK}$ were followed, with the only difference being the number and amount of ingredients weighed, and the new ingredients included to make the new formulations.

\subsection{Semi-Trained Analysis of Apam Balik Kuih}

The selection of semi-trained panel was adopted from a study by (Anupama et al., 2018). Developing a panel for sensory evaluation was done with screening tests and provided them with appropriate sensory training on the characteristics of flavour and texture characteristics and the density of products. The experiment was conducted at the Sensory Lab in Faculty of Hotel and Tourism Management, Universiti Teknologi MARA, Puncak Alam Campus. The testing material was procured from the local market in seksyen 7, Shah Alam.

\subsubsection{Recruitment Process}

An indisputably important element in the descriptive test was to find panellists who could use objective terms and expressions to describe food products. In order to understand the consumer well, at least 10 panellist members were required to detect the product. Therefore 25 people were hired. 15 of 25 people were taken from the foodservice department, and 10 of them were taken from the gastronomy department in Faculty of Hotel and Tourism Management, Universiti Teknologi MARA, Puncak Alam Campus.

\subsubsection{Screening Test}

The screening test consisted of three main steps. These include basic test, taste determination and colour density, and distinguishing test. The scoring system was used in the 1 st and 2 nd stages. Each of the 5 samples given was assigned 20 points. Each of the 5 samples given was given 20 points, and the panellists were expected to exceed 60 points. The panellists who passed 60 points were taken to the next stage.

\subsubsection{First Stage}

The aim of the first stage is to determine their ability to identify differences using dilute solutions that can represent basic flavours, for example, sour, bitter, salty, sweet and umami. For this reason, products including vinegar for sour taste, coffee for the bitter taste, salt for salty taste, sugar for sweet taste, and Ajinomoto for umami taste, were used. 
When the products were presented to the panellists, an odour test was also conducted. The products were given to the panellists in water, and they were asked to clean their mouths after each product test. At this stage, the first stage was applied to 25 people with 3 groups, and 18 out of 25 panellists were able to pass the next stage, exceeding 60 points.

\subsubsection{First Stage}

Phase 2 was carried out on 18 participants who passed the first phase. Firstly, the first colour analysis test was applied. Colour analysis test used blue food dye. 5 different colour tones were prepared, and while samples were prepared, $10 \mathrm{ml}$ water was filled into 5 different measuring cups and $1 \mathrm{ml}$ food colour in the first measuring cup, $2 \mathrm{ml}$ food colour in the second measuring cup, $3 \mathrm{ml}$ food colour in the third measuring cup, 4 $\mathrm{ml}$ of food colouring in the fourth measuring cup, and finally, $5 \mathrm{ml}$ of food colouring in the fifth measuring cup and mixed. The panellists were given 5 different blue shades in the form of complex sorting and were asked to sort from light to dark tone (Bright, Slightly Bright, Slightly Dark, Dark, Extremely Dark) according to the tone of the samples. As a result of the test, 17 out of 18 panellists passed 60 points and passed to the next stage of textural analysis test.

\subsubsection{Third Stage}

Phase 3, the textural analysis test, was applied to 17 panellists who passed the colour test successfully. Five different samples were used for textural characters (Soft, Slightly Soft, Slightly Hard, Hard, Extremely Hard) required for textural testing. According to the textures, from soft to hard, the inside of sandwich bread, cake, baguette, wafer and cracker were used. The samples were given to the panellists in the form of complex sequencing and were ordered from soft texture to hard texture. 17 panellists were divided into 5 groups of 3 panellists and one group of 2 panellists, and a textural test was performed. Of the 17 panellists, 15 passed 60 points to qualify for the next stage, which is the distinguishing test.

\subsubsection{Fourth Stage}

Stage 3 was the distinguishing test. 15 panellists who were successful in the textural analysis test, were used for distinguishing test. Sucrose required for use with this test was purchased from a supermarket in Shah Alam. For panellist selection, $10 \%$ and 50\% sucrose were diluted with water, one $10 \%$ diluted sucrose sample and two 50\% diluted sucrose samples were given to the panellists and asked which of the given samples was $10 \%$ diluted sucrose. 15 of the 17 panellists succeeded in this test.

\subsubsection{Training of Semi-Trained Panel}

In this section, panellists were given information about sensory analysis on ABK. This information was mainly about the criteria to be evaluated. During the evaluation, information was given about what should be taken into consideration or what subjects should be given importance and the meaning of the main criteria.

\subsubsection{Training of Semi-Trained Panel}

The sensory evaluation of the ABK was carried out by a 10-member semi-educated panel of students studying Gastronomy and Food Services from the Faculty of Hotel and Tourism Management, Universiti Teknologi MARA, Puncak Alam Campus. The panel members were asked to measure the terms describing sensory characteristics and to use the score to allocate appropriate matching taste. The scoring evaluation procedure was based on the evaluation of representative quality characteristics selected by Bornare \& Khan Safiya Ajaz Khan, (2015). A score list of 5 points was applied to the measurement scale. The sensory score is shown in Table 1. 
Table 1. Sensory attribute scored in sensory assessment of apam balik kuih (Bornare \& Khan Safiya Ajaz Khan, 2015)

\begin{tabular}{|c|c|c|}
\hline Sr. No & SENSORY TRAIT & Definition \\
\hline \multirow[t]{3}{*}{$\mathbf{A}$} & COLOUR & Light brown to very dark brown. (4.9 to 1$)$ \\
\hline & $\begin{array}{l}\text { 1) Light Brown } \\
\text { 2) Medium Brown }\end{array}$ & $\begin{array}{l}\text { Give a uniform light brown colour. } \\
\text { Give patches of light and dark brown. }\end{array}$ \\
\hline & $\begin{array}{l}\text { 3) Brown } \\
\text { 4) Dark Brown }\end{array}$ & $\begin{array}{l}\text { Uniform brown colour. } \\
\text { Very dark brown colour. }\end{array}$ \\
\hline \multirow[t]{4}{*}{ B } & APPEARANCE & Even surface to serious damage (4.9 to 1$)$ \\
\hline & 1) Even Surface & No breakages, regular shape, without damage. \\
\hline & 2) Slightly Uneven Surface & Hardly visible breakages, shape irregularities, without damage. \\
\hline & 3) Uneven & Visible breakages, irregular shape, serious damage. \\
\hline \multirow[t]{4}{*}{$\mathbf{C}$} & TEXTURE & Crisp to hard. (4.9 to 1) \\
\hline & 1) Crisp & Cookie suddenly breaks when a small amount of force is applied. \\
\hline & $\begin{array}{l}\text { 2) Crumbly } \\
\text { 3) Tender }\end{array}$ & $\begin{array}{l}\text { The cookie breaks easily, forming loose fragment in the mouth. } \\
\text { The cookie is easily broken down upon chewing. }\end{array}$ \\
\hline & 4) Hard Cookie & Withstands substantial force on the initial bite. \\
\hline \multirow[t]{5}{*}{$\mathbf{D}$} & MOUTHFEEL & Crunchy to teeth clogging (4.9 to 1$)$ \\
\hline & 1) Crunchy & $\begin{array}{c}\begin{array}{c}\text { Require repeated chewing to break cookie down, crunchy sound is } \\
\text { heard. }\end{array}\end{array}$ \\
\hline & 2) Granular & Small particles are detectable when the cookie is chewed. \\
\hline & 3) Flaky & $\begin{array}{l}\text { On chewing a rough paste is formed, containing large irregular } \\
\text { pieces. }\end{array}$ \\
\hline & 4) Teeth clogging & Particles stick in the mouth after the paste is swallowed. \\
\hline \multirow[t]{5}{*}{$\mathbf{E}$} & TASTE & Very pleasant to off-taste ( 4.9 to 1 ) \\
\hline & 1) Very pleasant & Very pleasant taste characteristic of cookies. \\
\hline & 2) Pleasant & Pleasant taste characteristic of cookies. \\
\hline & 3) Unpleasant & Taste uncharacteristic of cookies. \\
\hline & 4) Off taste & Giving off taste after eaten. \\
\hline $\mathbf{F}$ & $\begin{array}{c}\text { OVERALL } \\
\text { ACCEPTABILITY } \\
\end{array}$ & Outstanding to Unacceptable (4.9 to 1) \\
\hline & 1) Outstanding & $4.0-4.9$ \\
\hline & 2) Acceptable & $3.0-3.9$ \\
\hline & 3) Marginal & $2.0-2.9$ \\
\hline & 4) Unacceptable & $1.0-1.9$ \\
\hline
\end{tabular}

\subsection{Consumer Analysis of Apam Balik Kuih}

The method of analysis was adopted from Norhidayah, Noorlaila, \& Nur Fatin Izzati (2014). The consumer analysis was conducted at the Faculty of Hotel and Tourism Management, Universiti Teknologi MARA, Puncak Alam Campus, with 30 students between the age bracket of 20 and 23 years old. A set of three samples encompassing the original ABK, ABK made from a mixture of $60 \%$ LOCPF and $40 \%$ rice flour, and ABK made from $100 \%$ LOCPF was presented to a group of panellists made of 30 students and asked to evaluate the given sample based on 7- point hedonic scale with 1- being 'dislike extremely', and 7- being 'like extremely', and with six criteria (i.e. colour, appearance, texture, mouthfeel, taste and general acceptability) (Akonor et al., 2017; Norhidayah et al., 2014). The panellists did not have prior knowledge about the makeup of the various samples.

\subsection{Statistical Analysis}

For all tests, the means and standard deviations have been determined. The significant difference in mean values was measured at a significant point of $(p<0.05)$ with one-way analysis variance (ANOVA) accompanied by Fisher's check using Excel Software version 2016. 


\section{RESULT}

This section shows the result of the semi-trained panel and consumer acceptability of three various ABK. Table 2 shows the series of data retrieved from a semi-trained panel covering various aspects including colour, appearance, texture, mouthfeel, taste, and overall acceptability. The evaluation carried out by the semi-trained panel involved three different formulations that consisted of F1 (60\% WF + 40\% RF), F2 (60\% LOCPF + 40\% RF) and control sample F3 (100\% LOCPF), Table 2 below shows the result for semi-trained panel sensorial analysis for three different $\mathrm{ABK}$ formulations.

Table 2. The semi-trained panel sensorial analysis for three different apam balik kuih formulations

\begin{tabular}{ccccccc}
\hline Formulations & Colour & Appearance & Texture & Mouth Feel & Taste & $\begin{array}{c}\text { Overall } \\
\text { Acceptability }\end{array}$ \\
\hline F1 & $2.47 \pm 1.46^{\mathrm{a}}$ & $2.26 \pm 0.79^{\mathrm{a}}$ & $2.87 \pm 0.85^{\mathrm{a}}$ & $2.96 \pm 1.13^{\mathrm{a}}$ & $2.68 \pm 0.90^{\mathrm{a}}$ & $2.33 \pm 0.90^{\mathrm{a}}$ \\
F2 & $3.14 \pm 1.04^{\mathrm{a}}$ & $2.48 \pm 0.84^{\mathrm{a}}$ & $2.55 \pm 0.49^{\mathrm{a}}$ & $2.81 \pm 1.04^{\mathrm{a}}$ & $2.98 \pm 0.71^{\mathrm{a}}$ & $3.27 \pm 0.89^{\mathrm{a}}$ \\
F3 & $3.37 \pm 0.82 \mathrm{a}$ & $2.43 \pm 0.78 \mathrm{a}$ & $2.35 \pm 0.82 \mathrm{a}$ & $2.69 \pm 0.78 \mathrm{a}$ & $3.1 \pm 0.79 \mathrm{a}$ & $2.96 \pm 1.03 \mathrm{a}$
\end{tabular}

F1 (60\% WF + 40\% RF), F2 (60\% LOCPF + 40\% RF), and F3 (100\% LOCPF).

The 'a' value between the samples indicate a significant difference at $\mathrm{p}<0.05$.

Table 3 displays the data obtained from consumer acceptability covering various criteria's including colour, appearance, texture, mouthfeel, taste, and overall acceptability. The evaluation figured out by the consumer acceptability involved three different formulations that consisted of F1 (60\% WF + 40\% RF), F2 $(60 \%$ LOCPF $+40 \%$ RF) and control sample F3 (100\% LOCPF), Table 3 below shows the result for semitrained panel sensorial analysis for three different ABK formulations.

Table 3. The consumer panel sensorial analysis of three different apam balik kuih formulations

\begin{tabular}{lllllll}
\hline Formulations & Colour & Appearance & Texture & Mouth Feel & Taste & $\begin{array}{l}\text { Overall } \\
\text { Acceptability }\end{array}$ \\
\hline F1 & $5.79 \pm 0.82^{\mathrm{a}}$ & $5.79 \pm 0.97^{\mathrm{a}}$ & $5.25 \pm 1.18^{\mathrm{a}}$ & $5.21 \pm 1.05^{\mathrm{a}}$ & $5.04 \pm 1.03^{\mathrm{a}}$ & $5.17 \pm 0.91^{\mathrm{a}}$ \\
F2 & $4.88 \pm 0.98^{\mathrm{a}}$ & $5.08 \pm 0.96^{\mathrm{a}}$ & $4.71 \pm 1.11^{\mathrm{a}}$ & $4.88 \pm 0.84^{\mathrm{a}}$ & $5.13 \pm 0.89^{\mathrm{a}}$ & $5.08 \pm 0.82^{\mathrm{a}}$ \\
F3 & $4.08 \pm 0.97^{\mathrm{a}}$ & $4.12 \pm 1.02^{\mathrm{a}}$ & $4.33 \pm 1.29^{\mathrm{a}}$ & $4.17 \pm 1.26^{\mathrm{a}}$ & $4.29 \pm 0.07^{\mathrm{a}}$ & $4.42 \pm 1.05^{\mathrm{a}}$ \\
\hline
\end{tabular}

F1 (60\% WF + 40\% RF), F2 (60\% LOCPF + 40\% RF), and F3 (100\% LOCPF)

The ' $\mathrm{a}$ ' value between the samples indicate a significant difference at $\mathrm{p}<0.05$.

\section{DISCUSSION}

This section discusses on the result of sensorial evaluations which are semi-trained panel and consumer acceptability of three various ABK which are formulations that consisted of F1 (60\% WF + 40\% RF), F2 (60\% LOCPF + 40\% RF) and control sample F3 (100\% LOCPF).

\subsubsection{Colour}

The results showed that semi-trained panel mentioned F2 (60\% LOCPF + 40\% RF) and F3 (100\% LOCPF) ABK had more brownish tone than the F1 (60\% WF + 40\% RF) (i.e. control sample). The semitrained panel were evaluated using three different formulations of ABK (F3 (100\% LOCPF) > F2 (60\% LOCPF $+40 \% \mathrm{RF})>\mathrm{F} 1(60 \% \mathrm{WF}+40 \% \mathrm{RF}))$. Hence, this indicates that both F2 (60\% LOCPF + 40\% RF) and F3 (100\% LOCPF) had a darker brownish tone than the F1 (60\% WF + 40\% RF) ABK (control sample). This is due to the testa layer located between coconut shell and coconut meat found in LOCPF. In addition, no 
bleaching process was done in obtaining the LOCPF as compared to the wheat flour process (commercial flour). However, another reason could be from Millard reaction and caramelising of sugar, since both processes are instigated by heating (Bozdogan, Kumcuoglu, \& Tavman, 2019; Jeong \& Chung, 2019), whereby the Maillard reaction involves amino acids, whereas caramelisation simply involves the pyrolysis of certain sugars (Madhu, 2018). This can be explained by the lower scale rating of F1 (60\% WF + 40\% RF) ABK $(2.47 \pm 1.46)$ which represent the medium brown tone. In addition, F3 (100\% LOCPF) had the scale of $3.37 \pm 0.82$ which represent the brown tones, which is similar to that $\mathrm{F} 2(60 \% \mathrm{LOCPF}+40 \% \mathrm{RF}) \mathrm{ABK}$ where the scale obtained was $3.14 \pm 1.04$ which also described as brown tones. Although the F1 (60\% WF + 40\% RF) ABK (control sample) had a tone of light brown color $(2.47 \pm 1.46)$ as compared to the formulated ABK (F2 (60\% LOCPF $+40 \% \mathrm{RF})$ and $\mathrm{F} 3(100 \% \mathrm{LOCPF})$, there was no significant difference $(p>0.05)$ between them. Result of the non-significant difference $(p>0.05)$ of ABK (F1 (60\% WF + 40\% RF), F2 (60\% LOCPF + 40\% RF) and F3 $(100 \%$ LOCPF)) can be due to effect from Millard reaction \& caramelisation process involved during ABK making which may have led to a non-significant difference. In similitude to studies by Giuberti et al. (2018) and Jeong \& Chung (2019), the controls samples (rice flour, and wheat flour, respectively) had a more appealing colour as compared to the formulated ones (rice flour and alfalfa flour blends, and wheat flour and waxy rice flour blends, respectively). In similitude to studies by Giuberti et al. (2018) and Jeong \& Chung (2019), the control samples had more appealing colours as compared to the formulated ones. In contrast, a mild brown colour has been described in alfalfa seed flour \& rice flour (Giuberti et al., 2018) and mung bean Sohyun-waxy rice (Jeong \& Chung, 2019) which had rates of 6.7 and 4.3 respectively as compared to the control sample (rice flour, and wheat flour, respectively). The manifested colours exhibited by these cakes were as a result of the colour variations that are inherent in the flour materials and hence, the main reason behind the effect of LOCPF on ABK in terms of colour.

\subsubsection{Appearance}

The appearance is a utility used to trigger the appetite, more importantly in public eating places such as restaurants, where pieces of cakes and pies are exhibited for the view of the benefactors (Tenborg, 1950). During the formulation process, the appearance of the resultant kuih ABK was taken into account. The ABK made with $100 \%$ LOCPF (F3) manifested an appearance of $2.43 \pm 0.78$, while the ABK made with mixed flour, F2 (60\% LOCPF $+40 \%$ RF) showed an appearance of $2.48 \pm 0.84$. While the control sample ABK F1 $(60 \% \mathrm{WF}+40 \% \mathrm{RF})$ showed a $2.26 \pm 0.79$ appearance value (Table 2$)$. The results revealed that replacement of LOCPF at different percentages did not give much difference in terms of appearance $(p>0.05)$ between the $\mathrm{F} 1(60 \% \mathrm{WF}+40 \% \mathrm{RF}) \mathrm{ABK}$ (control sample) and the formulated ABK which were F3 (100\% LOCPF) and F2 $(60 \%$ LOCPF $+40 \%$ RF). A study on bakery products made with wheat flour and soybean (Glycine max) varieties done by Kaur (2019) showed that the biscuit which was made from a mixture of $80 \%$ wheat flour and $20 \%$ soybean (i.e. SL 744) flour was $8.0 \pm 0.67$, a biscuit made from wheat flour (control sample) was $6.4 \pm$ 0.97 due to protein and carbohydrate content of soybean flour. Another study on gluten-free baked products using quinoa flour done by Kaur \& Kaur (2017) showed that based on the appearance, $10 \%$ level of supplementation scored highest $(7.7 \pm 0.15)$ as compared to wheat flour $(7.2 \pm 0.20)$. Those studies' results are similar to the results of the three ABK formulations. However, although the appearance of F1 (60\% WF + $40 \% \mathrm{RF})$ was non-significantly lower $(p>0.05)$ than that of the ABK formulations (F2 (60\% LOCPF $+40 \%$ $\mathrm{RF})$ and F3 (100\% LOCPF)), three ABK formulations (F1 (60\% WF + 40\% RF), F2 (60\% LOCPF + 40\% RF), and F3 (100\% LOCPF)) had slightly uneven surface appearance as described by the semi-trained panel. The lower value of F1 (60\% WF + 40\% RF) which was the control sample can be due to the effect of the fibre content of LOCPF $(60.3 \pm 0.54 \mathrm{~g} / 100 \mathrm{~g})$ (Caliskan, Abdullah, \& Ishak, 2020). This is because crude fibre has an altering effect on the structural appearance since the insoluble dietary fibre present in coconut flour inhibits homogeneity of the texture but in turn encourages water absorption (Thiranusornkij, Thamnarathip, Chandrachai, \& Kuakpetoon, 2018). This can give the slightly uneven surface of F2 (60\% LOCPF + 40\% RF) and F3 (100\% LOCPF) ABK.

\subsubsection{Texture}

The semi-trained sensorial analysis results show that a slightly similar texture was rated for all tested ABK. Based on the results in Table 2, F3 (100\% LOCPF) ABK had a textural value of $2.35 \pm 0.82$, while F2 $(60 \% \mathrm{LOCPF}+40 \% \mathrm{RF})$ was $2.55 \pm 0.49$. The $\mathrm{F} 1(60 \% \mathrm{WF}+40 \% \mathrm{RF})$ which was the control sample of ABK had its textural value at the scale of $2.87 \pm 0.85$. In terms of texture, the F2 $(60 \% \mathrm{LOCPF}+40 \% \mathrm{RF})$ ABK had the closest proximity to the control sample F1 (60\% WF + 40\% RF), followed by the F3 (100\% 
LOCPF), the ranking of evaluation of ABK were F1 $(60 \% \mathrm{WF}+40 \% \mathrm{RF})>\mathrm{F} 2(60 \% \mathrm{LOCPF}+40 \% \mathrm{RF})>$ F3 (100\% LOCPF) and there was no significant difference $(p>0.05)$ among three formulations of ABK. No significant difference $(p>0.05)$ between the F1 $(60 \% \mathrm{WF}+40 \% \mathrm{RF})$ which was the control sample and formulated ABK (F2 (60\% LOCPF + 40\% RF) and F3 (100\% LOCPF)) indicates that all formulations had a textural crumbling structure as ranked by the semi-trained panel.

In addition, since the control sample was composed of $60 \% \mathrm{WF}$ and $40 \% \mathrm{RF}$, it possessed a better texture. The reason why the $\mathrm{F} 1(60 \% \mathrm{WF}+40 \% \mathrm{RF}) \mathrm{ABK}$ had high value in texture is due to its gluten content since, without gluten, baked goods do not hold their shape (Alfaro, 2019). However, the F2 ABK which had a mixture of $60 \%$ LOCPF and $40 \%$ RF had a better texture than F3 ABK which was made of $100 \%$ LOCPF because RF has a better homogeneity with water as compared to LOCPF which does not allow homogeneity in texture, but rather promotes greater water absorption capabilities due to fibre content (California, Pseudomonas, Lipases, High, \& Psychrotrophic, 1997; Thiranusornkij et al., 2018). In agreement to this, a study on functional and rheological properties of composite flour from sweet potato, maize, soybean, and XG has done by Julianti, Rusmarilin, \& Yusraini (2015), showed that the control bread (wheat flour) was higher in texture than the 6 formulations made from percentages of sweet potato, maize, and soybean. In contrast, another study on gluten-free muffin enriched with waxy rice flour done by Jeong \& Chung (2019), mentioned that the panellists evaluated the formulation of 50\% mung bean and 50\% Sohyun-waxy rice flour and it scored $41.2 \%$ higher in texture than the control muffins texture (wheat flour), because the Korean panellists preferred the sticky texture by the addition of the waxy rice flour.

\subsubsection{Mouthfeel}

The result of evaluation of mouthfeel acceptability by the semi-trained panel was F1 (60\% WF $+40 \%$ $\mathrm{RF})>\mathrm{F} 2(60 \% \mathrm{LOCPF}+40 \% \mathrm{RF})>\mathrm{F} 3(100 \% \mathrm{LOCPF})$. With respect to mouthfeel, Table 2 posits that the control sample F1 $(60 \% \mathrm{WF}+40 \% \mathrm{RF})(60 \% \mathrm{WF}+40 \% \mathrm{RF})$ was ranked as $2.96 \pm 1.13$, while $\mathrm{F} 2(60 \%$ $\mathrm{LOCPF}+40 \% \mathrm{RF})(60 \% \mathrm{LOCPF}+40 \% \mathrm{RF}) \mathrm{ABK}$ had $2.81 \pm 1.04$ mouth feel value, which happened to be the closest to the $\mathrm{F} 1(60 \% \mathrm{WF}+40 \% \mathrm{RF})$ which was the control sample $(p>0.05)$. However, ABK made of $100 \%$ LOCPF (F3) had a $2.69 \pm 0.78$ value. According to the evaluations of the panellists during the sensory analysis, the F1 $(60 \% \mathrm{WF}+40 \% \mathrm{RF})$ which was the control sample of ABK and the formulated ABK (F2 $(60 \% \mathrm{LOCPF}+40 \% \mathrm{RF})$ and $\mathrm{F} 3(100 \% \mathrm{LOCPF}))$ gave a granular feeling, and there was no significant difference $(p>0.05)$ between them. In agreement to this, a study on the effect of grapefruit albedo powder on fruit cake done by Qureshi et al. (2017), mentioned that formulation cake made with $5.60 \mathrm{~g}$ albedo flour and $75 \mathrm{~g}$ wheat flour had $12 \%$ better mouthfeel than control sample (wheat flour). The granular sensation of ABK is based on the original recipe ( $\mathrm{ABK}$ ), which involves the addition of peanuts which have a granular structure; hence, the resultant granular feeling in all samples. However, LOCPF inherently has a granular texture because of its dietary fibre content $(60.3 \pm 0.54 \mathrm{~g} / 100 \mathrm{~g})$ which does not dissolve in water (California et al., 1997; Caliskan et al., 2020). This can give a granular texture of ABK formulations. Therefore, it makes the addition of peanuts in the original recipe have a relative no significance in terms of the granular mouth feeling sensation.

\subsubsection{Taste}

Although there was no significant difference $(p>0.05)$ in taste evaluations, the F3 (100\% LOCPF) (100\% LOCPF) ABK had a taste value of $3.1 \pm 0.79$ and was considered as unpleasant due to its $100 \%$ coconut content as opposed to that of the formulations that contained $40 \%$ rice flour. The control sample $(60 \% \mathrm{WF}+$ $40 \% \mathrm{RF})$ and ABK which was formulated from the mixture of flour F2 (60\% LOCPF + 40\% RF) (60\% LOCPF $+40 \% \mathrm{RF})$ were valued $2.68 \pm 0.90$ and $2.98 \pm 0.71$, respectively, which indicates a pleasant taste. In terms of taste, most of the panellists liked the ABK in the following order: F2 (60\%LOCPF + 40\% RF) > F3 (100\% $\mathrm{LOCPF})>\mathrm{F} 1(60 \% \mathrm{WF}+40 \% \mathrm{RF})$ which shows that addition of LOCPF to the rice flour (RF) may increase the appetite because rice adds more viscosity structure on ABK which helps in making a creamy texture of ABK (Carson, 2019). According to Verma \& Malhotra (2019), when margarine is whipped with eggs and sugar, it adds a creamy texture to the cakes. In addition, based on a study by Hoyt (2017), a fat source is usually included to improve texture, moistness and overall flavour. Those can be the result of higher values of the taste of formulations of F2 (60\% LOCPF $+40 \% \mathrm{RF})$ ABK since LOCPF is already high in fat $(20.6 \pm 0.42 \mathrm{~g} / 100 \mathrm{~g}$ DW) (Caliskan et al., 2020), this can increase the taste of the ABK and add the more creamy and juicy structure of the formulated $\mathrm{F} 2(60 \% \mathrm{LOCPF}+40 \% \mathrm{RF}) \mathrm{ABK}$. 


\subsubsection{Overall Acceptability}

The panellists in the sensory analysis were asked to evaluate the colour, appearance, texture, mouth sensation, and taste, and finally, the overall acceptability. According to the feedbacks derived from the semitrained panellists as highlighted in Table 2, the most accepted ABK was the F2 (60\% LOCPF + 40\% RF) ABK, having a value of at $3.27 \pm 0.89$. Whereas, the F1 $(60 \% \mathrm{WF}+40 \% \mathrm{RF}) \mathrm{ABK}$ and the $\mathrm{F} 3(100 \% \mathrm{LOCPF}) \mathrm{ABK}$ values of $2.96 \pm 1.03$ and $2.33 \pm 0.90$, respectively. Holistically speaking, the F1 $(60 \% \mathrm{WF}+40 \% \mathrm{RF})$ and F3 (100\% LOCPF), which were two varieties of ABK were considered marginally acceptable. In terms of order of overall acceptability, the most accepted was the F2 $(60 \%$ LOCPF $+40 \% \mathrm{RF}) \mathrm{ABK}$, followed by the F3 (100\% LOCPF) ABK, then the F1 (60\% WF + 40\% RF) ABK (i.e F2 > F3 > F1). The reason why F2 (60\% $\mathrm{LOCPF}+40 \% \mathrm{RF}) \mathrm{ABK}$ was selected as most acceptable ABK by the semi-trained panel may be that, although in terms of appearance and taste all ABK were similar in value, F2 (60\% LOCPF + 40\% RF) ABK had high values as compared to $\mathrm{F} 1(60 \% \mathrm{WF}+40 \% \mathrm{RF})$ and $\mathrm{F} 3$ (100\% LOCPF) ABK.

\subsection{Consumer Acceptability}

Consumer acceptability analysis was conducted to identify the acceptability of the formulated ABK against the control sample. The consumer analysis was conducted at the UiTM sensorial laboratory within the Faculty of Hotel and Tourism, with 30 participants between the age of 20 and 23 years old. The panellists were asked to evaluate the given samples based on 7-point hedonic scale with 1- dislike extremely and 7- like.

\subsubsection{Colour}

Colour is an important sensory criterion for all food products due to its effect on customers' acceptability (Pal, Jacob, Kumar, Bharti, \& Pandey, 2018). The consumer analysis ratings are shown in Table 3 , whereby the $\mathrm{F} 1(60 \% \mathrm{WF}+40 \% \mathrm{RF}) \mathrm{ABK}$ had the best rating, with a value of $5.79 \pm 0.82$. The formulated $\mathrm{F} 2(60 \% \mathrm{LOCPF}+40 \% \mathrm{RF}) \mathrm{ABK}$ had a value of $4.88 \pm 0.98$ and took the second precedence, leaving the F3 (100\% LOCPF) ABK to take the least spot due to its rating value of $4.08 \pm 0.97$. The result evaluation of colour acceptability by the consumer panel was F1 $(60 \% \mathrm{WF}+40 \% \mathrm{RF})>\mathrm{F} 2(60 \% \mathrm{LOCPF}+40 \% \mathrm{RF})>\mathrm{F} 3(100 \%$ LOCPF) and there was no significant difference $(p>0.05)$ between the three ABK products. However, this resultant ordinance proved to be due to the degree of deviation in the tone of the formulated ABK (F2 $(60 \%$ $\mathrm{LOCPF}+40 \% \mathrm{RF})$ and $\mathrm{F} 3(100 \% \mathrm{LOCPF}))$ from the F1 (60\% WF + 40\% RF) ABK which had a light brown tone as compared to the darker tone observed from the formulated kuih, with the F3 (100\% LOCPF) ABK made with $100 \%$ LOCPF having a darker tone as compared to F2 (60\% LOCPF + 40\% RF). This is because the latter sample had rice flour content in its mixture, thereby it influenced the sample to have a lighter tone as compared to the sample formulated from 100\% LOCPF. This result is in concord with study on sponge cake supplemented with pumpkin flour executed by Hosseini Ghaboos, Seyedain Ardabili, \& Kashaninejad (2018), who mentioned that the addition of pumpkin flour increases darker of sponge cakes and results showed that sponge cake made with $5 \%$ pumpkin flour was 23.75 lower in colour value than control sample (wheat flour). Another study on the effect of coconut flour on gluten-free cookies done by Stoin (2016), showed that replacement of rice flour with coconut flour affects the colour, which decreased from $6.82 \pm 0.04$ in the control sample (rice flour) to $6.33 \pm 0.04$ in formulated samples ( $75 \%$ coconut flour and $25 \%$ rice flour). This lower value of formulations of ABK can be effected from the darker colour of LOCPF, which was come from testa layer of coconut and Maillard reactions and caramelisation.

\subsubsection{Appearance}

In the appearance category, the $\mathrm{F} 1(60 \% \mathrm{WF}+40 \% \mathrm{RF}) \mathrm{ABK}$ had the best results with a value of 5.79 \pm 0.97 , which was then followed by the F2 $(60 \% \mathrm{LOCPF}+40 \% \mathrm{RF}) \mathrm{ABK}$ with a value of $5.08 \pm 0.96$. The formulated sample F3 (100\% LOCPF) ABK had the least value of $4.12 \pm 1.02$. The result of evaluation appearance acceptability by the consumer panel were F1 (60\% WF + 40\% RF) > F2 (60\% LOCPF + 40\% RF) $>$ F3 $(100 \%$ LOCPF) and there was no significant difference $(p>0.05)$ between the three ABK products. 
Based on the feedback illustrated by Table 3, it was perceived that the F1 (60\% WF + 40\% RF) ABK and F2 $(60 \% \mathrm{LOCPF}+40 \% \mathrm{RF}) \mathrm{ABK}$ were slightly at parity in terms of appearance, while the $\mathrm{F} 3(100 \% \mathrm{LOCPF})$ ABK had a neutral result. The effect of the best appearance of F1 $(60 \% \mathrm{WF}+40 \% \mathrm{RF}) \mathrm{ABK}$ was due to its gluten content. Gluten helps to keep the structure and shape of kuih (Alfaro, 2019). Likewise, in the study on the effect of tamarind seed gum on the qualities of gluten-free cakes done by Shao, Yung, Yi, \& Wen (2020), the results of appearance of the control sample (wheat flour) was $48.23 \%$ higher than formulation cake (rice flour) because the rice flour doesn't have the capability to bind and emulsify water and air bubbles as wheat flour. According to Pal et al. (2018), protein can contribute to positive effects on texture and appearance besides providing essential nutrition. The replacement of WF with LOCPF can affect the appearance of formulations of ABK (F2 (60\% LOCPF + 40\% RF) and F3 (100\% LOCPF)) due to LOCPF having an appearance value $61.27 \%$ lower than WF. The mixture of rice and coconut sample used in the formulation of the desserts affected the general appearance of the samples. Hence, both the F1 (60\% WF + 40\% RF) and the $\mathrm{F} 2(60 \% \mathrm{LOCPF}+40 \% \mathrm{RF})$ had a better appearance due to the rice flour content in the samples unlike that of F3 which was made from 100\% LOCPF. This also lead the appearance of the 100\% LOCPF ABK to stray away the original form of the kuih.

\subsubsection{Texture}

Based on texture, Table 3 shows the values of the texture of the $\mathrm{F} 1(60 \% \mathrm{WF}+40 \% \mathrm{RF}) \mathrm{ABK}$ being $5.25 \pm 1.18$, the F2 $(60 \% \mathrm{LOCPF}+40 \% \mathrm{RF}) \mathrm{ABK}$ having a value of $4.71 \pm 1.11$ and the sample $\mathrm{F} 3(100 \%$ $\mathrm{LOCPF})$ having a value of $4.33 \pm 1.29$. The values of $\mathrm{F} 1(60 \% \mathrm{WF}+40 \% \mathrm{RF}) \mathrm{ABK}$ and the $\mathrm{F} 2(60 \% \mathrm{LOCPF}$ $+40 \% \mathrm{RF}) \mathrm{ABK}$ were not significantly different $(p>0.05)$, while that of the F3 (100\% LOCPF) ABK was considered neutral. It was evident that gluten (contained in wheat) had an effect on texture because gluten provides elasticity properties, and this helps to improve the texture of baking products (Gavin, 2019). Hence, the best value in relation to texture belongs to F1 $(60 \% \mathrm{WF}+40 \% \mathrm{RF}) \mathrm{ABK}$. However, the samples of F2 (60\% LOCPF $+40 \% \mathrm{RF})$ and F3 (100\% LOCPF) ABK had XG added to them as an elasticity supplement, which is also present in the original in the form of gluten. Furthermore, although the insoluble dietary fibre in LOCPF (60.3 $\pm 0.54 \mathrm{~g} / 100 \mathrm{~g}$ ) cannot dissolve in water, it can absorb it at high levels (California et al., 1997; Caliskan et al., 2020). This explains the reason behind the low textural rating of the F3 (100\% LOCPF) ABK. This is concurred by the study done by Thiranusornkij, Thamnarathip, Chandrachai, \& Kuakpetoon (2018), where samples which had rice flour had a better texture due to the fact that rice has a sticky texture, thus, it enhances the texture of the dessert during the formulation process. Another study on gluten-free snacks based on brown rice and chestnut flour carried out by Ahmad, John, Bosco, \& Ahmad (2017), revealed that texture value showed a decreasing trend with the increase in chestnut flour level in blend. Texture result of the control sample $(100 \% \mathrm{RF})$ was $7.06 \pm 0.07$, in $20 \%$ chestnut flour was $7.00 \pm 0.12$, and in $40 \%$, and $60 \%$ chestnut flour it was $6.27 \pm 0.18$, this may be because the addition of chestnut flour to the snacks contributed to high sugar content which is originally present in the chestnut flour, which can affect starch gelatinisation during the drying process and lead to texture changes. Finally, those studies show that the neutral status of formulated ABK (F2 (60\% LOCPF + 40\% RF) and F3 (100\% LOCPF)) can be due to the high dietary level and glutenfree structure of LOCPF, their granular texture, high water absorption, and less elasticity structure.

\subsubsection{Mouthfeel}

In terms of mouthfeel, the best results were in the order from $\mathrm{F} 1(60 \% \mathrm{WF}+40 \% \mathrm{RF}) \mathrm{ABK}$, to $\mathrm{F} 2$ (60\% LOCPF + 40\% RF) ABK, to F3 (100\% LOCPF) ABK, with values of $5.21 \pm 1.05,4.88 \pm 0.84$ and 4.17 \pm 1.26 , respectively (i.e. F1 $(60 \% \mathrm{WF}+40 \% \mathrm{RF})>\mathrm{F} 2(60 \% \mathrm{LOCPF}+40 \% \mathrm{RF})>\mathrm{F} 3(100 \% \mathrm{LOCPF}))$ and there was no significant difference $(p>0.05)$ among the three ABK products. However, it was evident that changes in texture do affect changes in mouthfeel. According to Moroni, Dal, \& Arendt (2009), baking of gluten-free flours is a challenge due to the lack of gluten proteins, as gluten is a protein which possesses a structure-forming ability that affects elastic properties of dough and contributes to the overall appearance and crumb structure of many baked products. Therefore, the removal of gluten in a gluten-free formulation is a very demanding task resulting in often low quality, poor mouthfeel, and low flavour products. Mouthfeel is essentially hinged with the rheological features of food during the first phase of consumption. Tactile sensations resulting from pressure and touch in the mouth inform about the size, shape, and first textured impressions such as juiciness, fluffiness, fattiness, oiliness, fluidity, viscosity, stickiness, dryness, and 
sandiness or graininess (Tiefenbacher, 2019). Hence, due to the inter-relationship between texture and mouthfeel, one can then see the rationale behind the similar rating of the mouthfeel in terms of the order of precedence just as that of the texture category.

\subsubsection{Taste}

In the taste category as shown in Table 3, the F2 $(60 \% \mathrm{LOCPF}+40 \% \mathrm{RF}) \mathrm{ABK}$ had the best rating of $5.13 \pm 1.03$, followed by the $\mathrm{F} 1(60 \% \mathrm{WF}+40 \% \mathrm{RF}) \mathrm{ABK}$ with a value of $5.04 \pm 0.89$, and then by the sample made with F3 (100\% LOCPF) ABK which had a value of $4.29 \pm 0.07$ (i.e. F2 (60\% LOCPF + 40\% RF) > F1 $(60 \% \mathrm{WF}+40 \% \mathrm{RF})>\mathrm{F} 3(100 \% \mathrm{LOCPF}))$ and there was no significant difference $(p>0.05)$ among the three ABK products. During the formulation of the F2 (60\% LOCPF + 40\% RF) ABK, the process was strictly adhered to match that of the original recipe. However, most of the participants showed a greater inclination towards it as compared to the F1 (60\% WF + 40\% RF), which was the control sample. This study is in agreement with the study on the influence of coconut flour addition on the gluten-free cookies done by Stoin (2016), which showed that the formulation of mixture flour was $19.85 \%$ higher in taste than control sample (rice flour) and formulation cookies (50\% rice flour and 50\% coconut flour) was $19.59 \%$ higher in aroma than the control sample. Another study on coconut-based gluten-free cookies done by Dhankhar \& Tech (2013), found that coconut cookies were $11.05 \%$ better taste than control sample (wheat flour) due to the strong taste and distinctive aroma of coconut powder. This can be the degree of harmony that LOCPF manifests with the rice flour in terms of fat-creamy texture as well as the aromatic flavours exhibited by the formulated ABK as a result of the inherent coconut oil. However, the sole use of LOCPF had a slightly negative effect on the aroma of the F3 (100\% LOCPF) ABK which was experienced by the sample having 100\% LOCPF.

\subsubsection{Overall Acceptability}

The overall acceptability based on consumer analysis is shown in Table 3 . The F1 $(60 \% \mathrm{WF}+40 \%$ $\mathrm{RF}$ ) ABK (i.e. control sample) had the highest rating of $5.17 \pm 0.91$, followed by the F2 (60\% LOCPF $+40 \%$ $\mathrm{RF}) \mathrm{ABK}$ which was a mixture of $60 \% \mathrm{LOCPF}$ and $40 \%$ rice flour that had a rating value of $5.08 \pm 0.82$, and finally F3 (100\% LOCPF) ABK made with 100\% LOCPF took last precedence with a rating value of $4.42 \pm$ 1.05 (i.e. F1 (60\% WF + 40\% RF) > F2 (60\% LOCPF + 40\% RF) > F3 (100\% LOCPF)), and there was no significant difference $(p>0.05)$ among the three ABK products. Although the consumer panel evaluated the $\mathrm{F} 1(60 \% \mathrm{WF}+40 \% \mathrm{RF})$ and F2 (60\% LOCPF + 40\% RF) ABK as slightly similar status, F3 (100\% LOCPF) had neutral status. This is because F3 (100\% LOCPF) formulation was neutral in all criteria's (i.e. colour, appearance, texture, mouthfeel, and taste). This study is in agreement to a study on the influence of quinoa roasting on gluten-free cakes done by Rothschild et al. (2015), who showed that control cake (wheat flour) was $31.57 \%$ higher in overall acceptability than formulated cake (i.e. 45 minute roasted quinoa flour). Another study on textural and sensorial properties of cookies prepared by wheat flour with unripe banana flour done by Norhidayah, Noorlaila, \& Nur Fatin Izzati (2014), mentioned that in terms of overall acceptability of cookies, control cookie scored $31.99 \%$ higher than formulated cookies (50\% banana flour and $50 \%$ wheat four) because it was observed that with an increase in banana flour substitution, there is a decrease in appearance, colour, taste, and overall acceptability of the cookies.

\section{CONCLUSION}

The semi-trained panels described the colour of the $\mathrm{F} 1: 60 \% \mathrm{WF}+40 \% \mathrm{RF}$ ABK as medium brown tone, while F2: $60 \% \mathrm{LOCPF}+40 \% \mathrm{RF}$ and F3: $100 \% \mathrm{LOCPF}$ as brown tone and uneven surface appearance were rated for all tested samples. In terms of the texture, all three samples were showed a crumbling structure and granular structure experienced on the mouthfeel. Based on taste, the F1: 60\% WF + 40\% RF and F2: 60\% LOCPF $+40 \%$ RF ABK had pleasant tastes, whilst the F3: 100\% LOCPF ABK had an unpleasant taste. This might have been realised due to the high aroma characteristic of LOCPF. In terms of overall acceptability, the semi-trained panels indicated that $\mathrm{F} 2: 60 \% \mathrm{LOCPF}+40 \% \mathrm{RF}$ ABK was acceptable and the other two tested ABKs: F1: 60\% WF + 40\% RF and F3: 100\% LOCPF were considered marginally acceptable.

The colour result of F1 ABK, the F2 ABK, and F3 ABK were $5.79 \pm 0.82,4.88 \pm 0.98$, and $4.08 \pm 0.97$ 
respectively. The F1 ABK was slightly liked more, but the F2 and F3 ABK were in the neutral status. However, this must have been due to the brownish colour of LOCPF. Based on appearance, the F1 ABK was 5.79 \pm 0.97 , the F2 ABK was $5.08 \pm 0.96$, and the F3 ABK was $4.12 \pm 1.02$. The resultant appearance outcome of the $100 \%$ LOCPF flour which happened to be in the neutral status was because, both the original and the formulated sample with the of the mixture of rice and coconut due to the presence of rice in their recipe. In terms of textural results, the F1, F2, and F3 ABK recorded 5.25 $\pm 1.18,4.71 \pm 1.11$, and 4.33 \pm 1.29 , respectively. Even though the F1 ABK was slightly liked, the F2 ABK and F3 ABK had neutral evaluations. This outcome might have been due to the level of influence that the gluten and fibre affected the texture. The mouth feels the result of the F1, F2, and F3 ABK were $5.25 \pm 1.18,4.88 \pm 0.84$, and $4.71 \pm 1.11$ respectively. The taste results of the $\mathrm{F} 1, \mathrm{~F} 2$, and F3 ABK were $5.04 \pm 1.03,5.13 \pm 0.89$, and $4.29 \pm 0.07$. The F1 ABK and F2 ABK were slightly liked whilst the F3 ABK had a neutral evaluation. However, this result could be hinged on the effect of the aromatic taste emanating from the LOCPF. The overall acceptability results suggested that F1 ABK and F2 ABK were slightly liked with evaluations of $5.17 \pm 0.91$ and $4.42 \pm 1.05$, respectively, whilst that of the F3 ABK had a neutral status with a $4.42 \pm 1.05$ evaluation stand. Based on these results from the semi-trained panel and consumer acceptability analysis, LOCPF showcases a high potential of being an excellent gluten-free alternative flour, having a high fibre content that could be useful for pharmaceutical and other food industry applications.

\section{ACKNOWLEDGEMENTS}

My special thanks goes to the Postgraduate Office of Faculty of Hotel and Tourism Management, UiTM for their ever welcoming arms and liberal dissemination of salient information whenever the need presents itself. In similitude, I also want to thank all the staff of the faculty who played a role in the success of this study.

\section{REFERENCES}

Adkins, S., Foale, M., \& Harries, H. (2010). Growth and production of coconut Perspectives in Coconut Production Glossary Bibliography Biographical Sketches. Encyclopedia of Life Support Systems.

Ahmad, S., John, S., Bosco, D., \& Ahmad, M. (2017). Journal of the Saudi Society of Agricultural Sciences Technological and nutritional properties of gluten-free snacks based on brown rice and chestnut flour. Journal of the Saudi Society of Agricultural Sciences, 0-5. https://doi.org/10.1016/j.jssas.2017.02.002

Akonor, P. T., Dziedzoave, N. T., Buckman, E. S., Mireku Essel, E., Lavoe, F., \& Tomlins, K. I. (2017). Sensory optimization of crackers developed from high-quality cassava flour, starch, and prawn powder. Food Science and Nutrition, 5(3), 564-569. https://doi.org/10.1002/fsn3.431

Alfaro, D. (2019). What Is Gluten?, Learn More About It and Its Role in Baking. Retrieved from https://www.thespruceeats.com/what-is-gluten-995123

Anupama, S. M., Khan, H., \& Radha, K. (2018). Development of panel by selecting semi-trained participants for sensory evaluation. International Journal of Advance Research, Ideas and Innovations in Technology, 4(3), 827-830. Retrieved from www.ijariit.com

Barge, K. R., \& Divekar, S. P. (2018). Development of coconut milk residue and jackfruit seed enriched biscuit. International Journal of Agricultural Engineering, 11(2), 373-378. https://doi.org/10.15740/has/ijae/11.2/373-378

Biesiekierski, J. R. (2017). What is gluten? Journal of Gastroenterology and Hepatology (Australia), 32, 7881. https://doi.org/10.1111/jgh.13703

Bornare, \& Khan Safiya Ajaz Khan. (2015). Physical and Sensory Evaluation of Cookies Incorporated with Oats and Honey. International Journal of Engineering Research And, V4(08), 407-411. https://doi.org/10.17577/ijertv4is080395

Bozdogan, N., Kumcuoglu, S., \& Tavman, S. (2019). Investigation of the effects of using quinoa flour on gluten-free cake batters and cake properties. Journal of Food Science and Technology, 56(2), 683-694. https://doi.org/10.1007/s13197-018-3523-1 
California, F., Pseudomonas, E. F., Lipases, B., High, U., \& Psychrotrophic, F. (1997). Dietary fibres: Nutritional, (1978), 41-48.

Caliskan, A., Abdullah, N., \& Ishak, N. (2020). Chemical Properties of Left Over Coconut Pulp Gluten Free Flour. In Kuala Lumpur International Conference on Business, Education, Social Sciences and Technology (pp. 1-11). Kuala Lumpur: Asian Scholars Network.

Carson, L. (2019). Make Baking Easier with Pre-gelatinized Rice Flour. Retrieved from https://bakerpedia.com/make-baking-easier-with-pre-gelatinized-rice-flour/

Dhankhar, P., \& Tech, M. (2013). A Study on Development of Coconut Based Gluten Free Cookies, 2(12), $10-19$.

Gavin, J. (2019). What is Gluten? and Why it's so Important. Retrieved from https://www.jessicagavin.com/what-is-gluten-and-why-its-important/

Giuberti, G., Rocchetti, G., Sigolo, S., Fortunati, P., Lucini, L., \& Gallo, A. (2018). Exploitation of alfalfa seed (Medicago sativa L.) flour into gluten-free rice cookies: Nutritional, antioxidant and quality characteristics. Food Chemistry, 239, 679-687. https://doi.org/10.1016/j.foodchem.2017.07.004

Hager, A. S., Axel, C., \& Arendt, E. K. (2011). Status of carbohydrates and dietary fiber in gluten-free diets. Cereal Foods World, 56(3), 109-114. https://doi.org/10.1094/CFW-56-3-0109

Hamzah, H., Karim, M. S. A., Othman, M., Hamzah, A., \& Muhammad, N. H. (2014). Challenges in Sustaining the Malay Traditional Kuih among Youth. International Journal of Social Science and Humanity, 5(5), 472-478. https://doi.org/10.7763/ijssh.2015.v5.502

Hosseini Ghaboos, S. H., Seyedain Ardabili, S. M., \& Kashaninejad, M. (2018). Physico-chemical, textural and sensory evaluation of sponge cake supplemented with pumpkin flour. International Food Research Journal, 25(2), 854-860.

Hoyt, A. (2017). The Chemistry of Cake Ingredients. Retrieved from https://recipes.howstuffworks.com/cakes1.htm

Jeong, D., \& Chung, H. J. (2019). Physical, textural and sensory characteristics of legume-based gluten-free muffin enriched with waxy rice flour. Food Science and Biotechnology, 28(1), 87-97. https://doi.org/10.1007/s10068-018-0444-8

Jnawali, P., Kumar, V., \& Tanwar, B. (2016). Celiac disease: Overview and considerations for development of gluten-free foods. Food Science and Human Wellness, 5(4), 169-176. https://doi.org/10.1016/j.fshw.2016.09.003

Julianti, E., Rusmarilin, H., \& Yusraini, E. (2015). Functional and rheological properties of composite flour from sweet potato, maize, soybean and xanthan gum. Journal of the Saudi Society of Agricultural Sciences. https://doi.org/10.1016/j.jssas.2015.05.005

JWN. (2019). Dish Menu List/Jabatan Warisan Negara. Retrieved May 23, 2019, from http://heritage.gov.my/index.php/en/

Kaur, H. (2019). Development and sensory evaluation of value added bakery products developed from germinated soybean ( Glycine max ) varieties, 11(1), 211-216. https://doi.org/10.31018/jans.v11i1.2019

Kaur, S., \& Kaur, N. (2017). Development and sensory evaluation of gluten free bakery products using quinoa ( Chenopodium Quinoa) flour, 9411.

Lee, A. R., Ng, D. L., Dave, E., Ciaccio, E. J., \& Green, P. H. R. (2009). The effect of substituting alternative grains in the diet on the nutritional profile of the gluten-free diet. Journal of Human Nutrition and Dietetics, 22(4), 359-363. https://doi.org/10.1111/j.1365-277X.2009.00970.x

Madhu. (2018). Difference Between Maillard Reaction and Caramelization. Retrieved from https://www.differencebetween.com/difference-between-maillard-reaction-and-caramelization/

Moroni, A. V, Dal, F., \& Arendt, E. K. (2009). Sourdough in gluten-free bread-making: An ancient technology to solve a novel issue ? Food Microbiology, 26(7), 676-684. https://doi.org/10.1016/j.fm.2009.07.001

Nazri, M., Raji, A., Ab, S., Adibah, F., \& Ishak, C. (2017). Past and present practices of the Malay food heritage and culture in Malaysia. Journal of Ethnic Foods, 4(4), 221-231. 
https://doi.org/10.1016/j.jef.2017.11.001

Norhidayah, M., Noorlaila, A., \& Nur Fatin Izzati, A. (2014). Textural and sensorial properties of cookies prepared by partial substitution of wheat flour with unripe banana (Musa x paradisiaca var. Tanduk and Musa acuminata var. Emas) flour. International Food Research Journal, 21(6), 2133-2139.

Öhlund, K., Olsson, C., Hernell, O., \& Öhlund, I. (2010). Dietary shortcomings in children on a gluten-free diet. Journal of Human Nutrition and Dietetics, 23(3), 294-300. https://doi.org/10.1111/j.1365277X.2010.01060.X

Opalyn Mok. (2016). Malaysian kuih: A marriage of flavours and cultures | Eat/Drink | Malay Mail. Retrieved July 21, 2019, from https://www.malaymail.com/news/eat-drink/2016/03/27/malaysian-kuih-amarriage-of-flavours-and-cultures/1087719

Pal, V., Jacob, T., Kumar, V., Bharti, B. K., \& Pandey, N. (2018). Development and quality evaluation of multigrain cookies, 7(7), 1002-1007.

Qureshi, A., Ainee, A., Nadeem, M., Munir, M., Qureshi, T. M., \& Jabbar, S. (2017). Research Article Effect of Grape Fruit Albedo Powder on the Physicochemical and Sensory Attributes of Fruit Cake, (2008).

Rothschild, J., Rosentrater, K. A., Onwulata, C., Singh, M., Menutti, L., Jambazian, P., \& Omary, M. B. (2015). Influence of quinoa roasting on sensory and physicochemical properties of allergen-free, glutenfree cakes. International Journal of Food Science and Technology, 50(8), 1873-1881. https://doi.org/10.1111/ijfs.12837

Seow, C. C., \& Gwee, C. N. (1997). Coconut milk: Chemistry and technology. International Journal of Food Science and Technology, 32(3), 189-201. https://doi.org/10.1046/j.1365-2621.1997.00400.x

Shao, C. W., Yung, S. S., Yi, W. T., \& Wen, C. S. (2020). processes The E ff ect of Tamarind Seed Gum on the Qualities of.

Shepherd, S. J., \& Gibson, P. R. (2013). Nutritional inadequacies of the gluten-free diet in both recentlydiagnosed and long-term patients with coeliac disease. Journal of Human Nutrition and Dietetics, 26(4), 349-358. https://doi.org/10.1111/jhn.12018

Stoin, D. (2016). Researches regarding the influence of coconut flour addition on the nutritional value of gluten - free cookies, 1 .

Tenborg, I. M. (1950). April 18, 1950 I. M. TENBORG, 1949-1951.

Thiranusornkij, L., Thamnarathip, P., Chandrachai, A., \& Kuakpetoon, D. (2018). Physicochemical Properties of Hom Nil ( Oryza sativa) Rice Flour as Gluten Free Ingredient in Bread, 1-13. https://doi.org/10.3390/foods7100159

Tiefenbacher, K. (2019). Glossary of Terms in Wafers, Waffles and Adjuncts. Elsevier Inc. https://doi.org/10.1016/B978-0-12-809437-2.00010-1

Timothy G. Roufs, \& Kathleen Smyth Roufs. (2014). Sweet Treats around the World An Encyclopedia of Food and Culture. ABC-CLIO.

USDA. (2018). U.S. Department of Agriculture. Retrieved July 20, 2019, from https://www.usda.gov/

Verma, V., \& Malhotra, M. (2019). Importance of Shortening \& Margarine In Baking. Retrieved from http://www.foodprocessingbazaar.com/articles/3818-importance-of-shortening-margarine-inbaking.html 